\title{
Evaluation of Content Curriculum in Kindergarten
}

\author{
Nurbiana Dhieni ${ }^{1}$ \\ Sofia Hartati ${ }^{2}$ \\ Sri Wulan ${ }^{3}$ \\ Universitas Negeri Jakarta
}

DOI: https://doi.org/10.21009/10.21009/JPUD.131.06

Accepted: $15^{\text {th }}$ March 2019. Published: $30^{\text {th }}$ April 2019

\begin{abstract}
This study aims to map the quality of the curriculum used by kindergartens in Jakarta. The mapping curriculum was done by looking at the suitability curriculum with stages of child development, accommodating children's needs, using child-centered learning processes, and utilizing technological developments. Subjects were 32 kindergarten institutions in Jakarta (North Jakarta and Jakarta Central), from 14 districts. Kindergarten institutions studied were chosen to represent each district. In collecting data, the researchers conducted an analysis content of curriculum and interview with respondents and informants in kindergarten institutions either principals or teachers in schools who selected as samples. The research team collected information as a result of observation and described in-depth interviews in the diary of researchers - the data collected from 16 kindergartens that are willing to research subject. The data consisted of curriculum documents, curriculum evaluation instruments and interviews' the results analyzed qualitatively from the beginning of the data collection process include data reduction, data presentation, and conclusion.
\end{abstract}

Keyword: Content, Curriculum, Evaluation, Kindergarten.

(C) 2019 Early Childhood Education Post Graduate Program UNJ, Jakarta e-ISSN (Online Media) : 2503-0566

P-ISSN (Print Media) : 1693-1602

\footnotetext{
${ }^{1}$ Corresponding Author:

Nurbiana Dhieni

Gedung Hatta. Lantai 4

Jln Rawamangun muka, Jakarta Timur, Indonesia

Email: ndhieni@unj.ac.id
} 


\section{INTRODUCTION}

The Early Childhood Education Institute (ECE) is a means of socializing education that is suitable for children's development, must provide examples of good learning for early childhood. The process of early childhood education and learning should be carried out to provide meaningful concepts through real experience. Real experience allows children to optimally carry out activities, curiosity and place the position of educators as mentors, mentors and facilitators for children. Through the education process, it is expected to avoid forms of learning that are only oriented to the willingness of teachers to place children passively and make the teacher dominant in the class. However, whatever form of learning is given to children; it will depend on the curriculum developed by Early Childhood Education (ECE) institutions. A curriculum is a guideline of learning activities between teachers and children. The curriculum becomes a benchmark for goals, materials, methods, media, and evaluation of learning that carried out at Early Childhood Education (ECE) institutions. If the curriculum is excellent and meets curriculum principles, the ongoing learning will be useful for early childhood development.

The development of the Early Childhood Education (ECE) curriculum currently depends on the capacity of the staff owned by the educational institution or mimics the curriculum development of other educational institutions. So, the philosophy of the curriculum is not comprehensively understood by both educators and managers of Early Childhood Education (ECE) institutions. While the Directorate for Early Childhood Education (ECE) at the Ministry of Education and Culture has a function as a facilitator providing guidance and training in the preparation of curriculum in Early Childhood Education (ECE) institutions. Therefore, it is essential to evaluate the curriculum developed in ECE institutions, especially in kindergarten (TK). This evaluation obtained information on the extent of the curriculum developed by the needs of early childhood development and solutions that could overcome obstacles related to the development of the early childhood curriculum.

A role of the curriculum in learning is crucial. It is a guide in all learning process. The curriculum contains learning planning which includes learning activities and materials, learning objectives, learning methods, learning media, and learning evaluation. Thus, an effective curriculum can be a guide for higher quality learning. Curriculum development if made into a weekly activity plan or daily activity plan will be easier to understand and implement. It is very important to know the extent to which the curriculum used by the tenth kindergarten is by looking at the provisions and concepts of early childhood education at the institution.

In finding out the quality curriculum used in kindergarten, research is needed. It can be done through curriculum evaluation in kindergarten. The results of curriculum evaluation can be the main data for each component of society, academics, and practitioners about the advantages and disadvantages in the form of kindergarten curricula in the Jakarta area. Thus, the results of this study can provide suggestions for the development of the next curriculum in kindergarten.

The results of curriculum evaluation will bring up the kindergarten curriculum that is used to carry out learning in accordance with the child's developmental needs. It is important to consider that every child has different needs at each stage of age so that he needs different stimulation. The evaluation results will also represent the extent of kindergarten curriculum used that has internalized the culture of Indonesian society as a manifestation of children's nationalism. Thus, we can know the concept of childhood from an early age and what stimulation will be given to increase the love and pride of children to be part of Indonesian society. Research conducted by Odom et al., (2019) which aims to test the efficacy of the curriculum for the success of the Children's 
School (CSS) for 4-year-old children enrolled in preschool programs designed to prepare them for success in their initial state school classes. The study takes place in preschool classes located in five regionally distributed states, all of which include children with disabilities and other learning needs. Participants were 1,117 children from three subgroups (i.e., children living in poverty, children learning English, and children with disabilities identified). This curriculum is also examined for children from groups who have challenging behaviors. The findings show positive effects on various assessments of vocabulary mastery, letters of knowledge, mathematics, and solving social problems in early childhood.

A curriculum evaluation will also examine the curriculum ability in recent adapting technology and information and review the easiness curriculum to implement in early childhood learning. According to the result, information about the strengths and weaknesses of the curriculum will obtain in adapting technology and information. The results of curriculum evaluation decisions by researchers can be made into a form of curriculum that is in accordance with current technological and information developments. Likewise, in the implementation of the learning curriculum in early childhood education institutions, through curriculum evaluation will get information about the ease and difficulties in forming and developing a more effective curriculum. This information helps to overcome the difficulties that still exist in the curriculum implementation.

Based on the results of first-year research in the East Jakarta, it showed that there were still many kindergartens that had not been able to develop the curriculum appropriately. Percentage obtained by $67 \%$ of curriculum conformity assessments in kindergartens studied, tend to have a childcentered curriculum, $7 \%$ for content or learning material in curriculum and activities, $60 \%$ for giving attention to the children needs in curriculum, $6 \%$ for achieving curriculum objectives, $27 \%$ for easing in daily implementation, $6 \%$ for helping curriculum to build concepts and skills, $40 \%$ for internalizing cultural values in curriculum, and 20\% for adapting technology and information development in curriculum (Dhieni \& Utami, 2013). It is expected that the second-year research about the evaluation of curriculum content in North Jakarta and Central Jakarta would get more accurate results.

The meaningful and concrete learning experiences are designed, implemented and evaluated in a systematic guideline called the curriculum. According to Kostelnik, Soderman, \& P (2007, p. 216), the curriculum is all organized educational experiences provided for children by the early childhood program. These experiences can take place inside the classroom or beyond, involving educators, family members, and other people in the community. In its written form, the curriculum includes stated goals and objectives, strategies and activities aimed at supporting all aspects of children's development and learning, and methods of assessing children's progress and program effectiveness.

The curriculum is a series of learning program strategies and plans as well as all organized educational experiences provided to children through the learning process at the Early Childhood Education (ECE) institution. This experience can be done both inside and outside the classroom involving educators, family members, and other people in the community. In written form, the curriculum includes national goals, institutional goals, strategies and objectives of activities that support all aspects of child development and learning. There are assessments to see child improvement and effectiveness of a program. The curriculum can interpreted as a set of learning activities that are deliberately planned to be implemented in order to prepare and lay the foundations for further child self-development. 
Curriculum development must describe various things including knowledge about early childhoods, individual characteristics of children, cultural values, parental desires and knowledge needed by children in society. Shepard suggested following curriculum principles Eliason \& Jenkins (2008, p. 65): a) all children can learn; b) material challenges high-level thinking and problem solving; c) diverse learners are given equal opportunities; d) learning relationships within and outside of school authenticated; e) children encouraged to realize the importance of the habit; and f) children do the practice of democracy in society.

According to Jackman (2012, p. 37) compiling a curriculum that is appropriate with early childhood have to consider: a) child-centered curriculum or according to the children's willingness; $b$ ) curriculum supports all child development through planned experience to build what children want to know and be able to do; c) curriculum encourages children to learn by conducting experiments, exploration, and discoveries that will build self-control and a positive self-image; d) curriculum supports and serves children with special needs in an inclusive environment; e) curriculum provides opportunities for children of diverse cultures and languages; f) curriculum invites creativity through opportunities for discovery and activities that are not assessed to appear tolerant and respect people's work; g) curriculum facilitates physical activities and plays through activities that integrated with daily activities; and h) curriculum involves teachers and families. A developing curriculum is not compiled based on the willingness of teachers, manager, or parents but takes into children needs as an individual and as a member of the community in development and learning. Therefore, the curriculum really must be child centered.

Based on the explanation above, the early childhood curriculum must be following the children needs and development. Also, the curriculum must contain learning content that will apply to each school. The learning content must include children's knowledge, skills, and creativity. The play activities program developed consisted of social and emotional development, language development, self-understanding, community and world, creative expression and respect for art.

A curriculum has various models. According to Crosser(Jackman, 2012, p. 37), curriculum model is a structured or organized framework used in deciding everything from policies and priorities to teaching methods and assessment procedures. The curriculum model is beneficial in planning and managing experiences. As teachers, they need to learn more about models and programs for early childhood curriculum development.

According to Montessori in (Hainstock, 2002, pp. 10-11), child development is a sensitive period and easy to receive stimuli from his environment. Based on the theory of child development, it believed that every child is born with more than one talent. These talents are potential. So, children need education that supports their development by enriching their playing environment. There are principles that Maria Montessori believes are: (1) Respecting Children. Each child is unique so that educators in providing services must be individualized. Children have different abilities from one another. Therefore, educators must respect children as individuals who have extraordinary abilities. (2) Absorbent Mind. Information that enters through the child's senses quickly absorbed into the brain. The absorption of a child's brain can liken to a sponge that absorbs water quickly. Educators should not be mistaken in giving the concept to children. (3) Sensitive Periods. The sensitive period can describe as a potential that will develop very rapidly at certain times. This potential will die and will not appear again if it is not given the opportunity to develop. (4) The Environment Prepared. Educators should prepare an environment that can lead to the desire of children to learn many things. The environment prepared must be designed to facilitate the needs 
and interests of children. So, educators must provide facilities and infrastructure that are appropriate to the needs and interests of children. An environment arranged in various settings so that children do not depend on adults. The environment prepared makes children free to move, play and work. (5) Self-education. Environment prepared by educators. This allows children to explore, express, and make many things without the help of adults - the results obtained by children because their works are more extraordinary and unusual than if they helped. The work produced is diverse and unique while those assisted with the work of children are the same. So actually, children can learn on their own if we provide facilities according to their potential and interests.

According to the American Montessori Society (Roopnarine \& Johnson, 2005, p. 375), Montessori model curriculum content is given for children aged 3 - 6 years. There are four primary content, namely practical life, sensorial, language, and mathematics. Additionally, there are music, art, movement or motorists and drama.

Based on Roopnarine \& Johnson (2005) and Gestwicki, (2007), an idea of the Bank Street approach consists of: (1) children are active learners, researchers, explorers, and artists; (2) learning occurs in a social context where children learn through interaction with their environment; and (3) understanding of cognitive and affective development is an interconnection or not separate. A basis of the Bank Street model uses the developmental-interaction approach. This approach fosters cognitive function, collects and sorts of information makes judgments, gives reasons, solving problems, using a system symbol. It cannot be separated from the process of personal and interpersonal growth, the development of self-esteem and identity, the internalization of self-control, the capacity to respond independently and to relationships with others.

Kindergarten curriculum development is the development of a set of playground plans designed to maximize learning interactions and can enrich the kindergarten children learning experience in order to produce potential behavioral changes (positive behaviors).

Some criteria for developing the kindergarten curriculum are as follows;

(1) Curriculum suitability used with aspects and stages of child development.

(2) Curriculum orientation used is child centered.

(3) Learning content or material in the curriculum.

(4) Curriculum used pays attention to children's needs.

(5) Easiness curriculum implemented in the form of a daily learning program.

(6) The curriculum helps children build concepts and skills through a combination of topics and material.

(7) Consistency achievement of curriculum objectives obtained some children.

(8) Curriculum used shows the internalization of cultural values that exist in Indonesian society.

(9) Curriculum ability to adapt technological and information developments.

A curriculum that has been used needs to be evaluated periodically. To evaluate the curriculum needs to be determined the purpose of evaluation and design evaluation consisting of evaluation models and research methods. Then the instrument is determined to capture data and information sources. If we understand curriculum evaluation above, the curriculum can view as research. To support the definition of curriculum evaluation, Hasan (2008, p. 41) said that curriculum evaluation as an effort to collect information about the curriculum systematically and used as a consideration of the assessment and meaning of the curriculum in a particular context. It means that the curriculum cannot be valid all the time because there are limitations in the context of time.

The evaluation goal was designed and implemented as follows: (Hasan, 2008, pp. 42-43)

(1) Providing information about the development implementation and curriculum implementation as advice in making decisions. 
(2) Determining the success and failure of a curriculum and contributing factors in a particular environment.

(3) Developing various alternative problem solving that can be used in efforts to improve the curriculum.

(4) Understanding and explaining the characteristics and implementation of a curriculum.

Also, another goal of curriculum evaluation is developing a curriculum that is currently in effect and how the curriculum affects children.

\section{METHODS}

An evaluation conducted was an assessment of the curriculum used by kindergarten. The evaluation target was the second-year research in kindergartens at North Jakarta and Central Jakarta. The characteristics of kindergartens in those area grouped into superior kindergarten and regular kindergarten. Research target set for kindergarten in Jakarta area is 15 kindergarten and in North Jakarta is 17 kindergarten. So, the research target was 32 kindergarten institutions in 14 subdistricts. In each administrative area, a representative kindergarten organization is chosen. The selection of kindergarten institutions as a place for observation carried out for reasons of time and energy efficiency.

An assessment scope included the curriculum suitability used with the stages of child development, child-centered of curriculum orientation, children needs, internalization of Indonesian people's cultural values into the curriculum used, and curriculum ability to adapt technological developments and information, and convenience curriculum to be implemented in learning. The scope of evaluation is integrated into the evaluation design developed.

North Jakarta has approximately 227 kindergartens. It spread in 6 sub-districts namely Kelapa Gading, Pademangan, Tanjung Priok, Cilincing, Penjaringan, and Koja. Central Jakarta had approximately 211 kindergartens. It spread in 8 sub-districts namely Tanah Abang, Cempaka Putih, Menteng, Kemayoran, Senen, Sawah Besar, Johar Baru, and Gambir. From 32 institutions, 16 kindergartens institutions were willing to submit curriculum documents.

Kindergartens in North Jakarta and Central Jakarta have variations in the curriculum used for children's learning processes. The curriculum variation showed from the model and curriculum reference used. Kindergarten was a formal pathway Early Childhood Education (ECE) institution intended for children aged 4-6 years. The second year's research on kindergartens in North Jakarta and Central Jakarta, which was netted as research targets that could be categorized as among others; Public Kindergarten, Private Kindergarten, Christian Kindergarten, and Islamic Kindergarten. The four kindergartens had different characteristics.

Evaluation is done by evaluating the kindergarten curriculum developed by kindergarten with a qualitative model. The curriculum assessment carried out by Early Childhood Education (ECE) curriculum experts. The systematics of the evaluation process were as follows;

(1) Determined the kindergarten that will be assessed in the curriculum. The kineticist kindergarten grouped into superior kindergarten and regular kindergarten, with each group represented by several kindergartens in North Jakarta and Central Jakarta.

(2) Every curriculum obtained that assessed by several pre-determined Early Childhood Education (ECE) curriculum experts. Each appraiser used an assessment instrument developed by the research team. 
(3) Assessment results analyzed according to the framework that has been built in the evaluation design to see the achievement of the evaluation indicators.

Curriculum evaluation design included assessment aspects, assessment indicators, and assessment descriptions. The assessment aspect showed the principles of developing a kindergarten curriculum. The measurement of the principles of curriculum development was an indicator that will be assessed to determine the accuracy curriculum developed by the target evaluation of kindergarten. The description assessment was an explanation of the limits of assessment based on the aspects and indicators as a means of equating perceptions between assessors. Thus, the evaluation phase of the implemented curriculum described as follows:

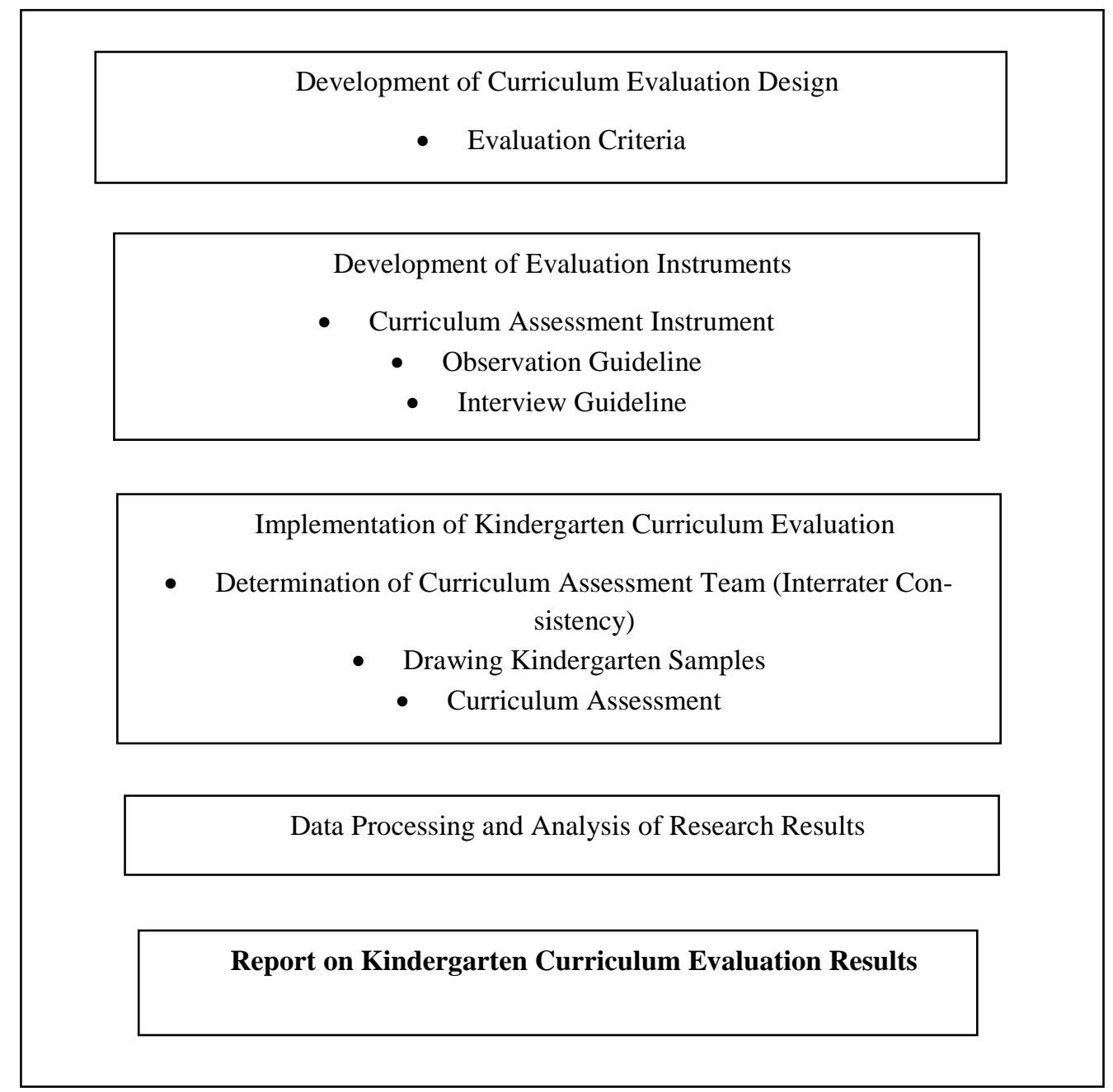

Picture 1. Research Design for Curriculum Evaluation

Data collection is the result of an assessment by an Early Childhood Education curriculum expert (ECE) and has credibility in assessing qualitative data. The assessment results were information provided by the assessor based on the assessment indicators contained in the instrument.

Data collections were interviews and observations conducted by the research team. It included non-numerical data that explained the background of curriculum development and how the curriculum implemented in daily learning in the kindergarten. Data analysis used qualitative data analysis - the result data of interviews and observations conducted by the evaluator team. Qualitative data analysis techniques carried out were data reduction, display (data presentation), and verification (conclusion). 
Kindergarten institutions spread in 6 sub-districts in North Jakarta and eight sub-districts in Central Jakarta. Generally, 32 kindergarten institutions asked for their willingness to become research subjects, and they expressed their willingness. However, during the data collection process, only 16 kindergartens were willing to provide curriculum documents. The rest refuses for different reasons.

\section{RESULT AND DISCUSSION}

Based on the finding, an analysis of curriculum documents and questionnaires given to 16 kindergarten institutions are as follows:

\subsection{Curriculum suitability used with aspects and stages of child development.}

Based on the finding, an analysis of curriculum documents and questionnaires given to 16 kindergarten institutions are as follows:

Data of public kindergarten groups have the same curriculum form, not found in the characteristics of each institution. This public kindergarten has a match between aspects of the curriculum and stages of child development. The development aspects are not consistent between the curriculum and the structure of the learning program. Private kindergartens have understood that each institution should have a curriculum and following the aspects and stages of child development. However, some institutions do not have a curriculum in the document. There are Christian kindergartens which have the specific curriculum as in the public kindergarten, and some others have a curriculum that oriented towards aspects and stages development. Likewise, with Islamic kindergarten, they have the same curriculum as the public kindergarten, and some others have the same curriculum with each other. Even so, Islamic kindergarten has a curriculum that is by the aspects and stages of child development.

\subsection{Curriculum orientation used is child-centered.}

Based on the findings of public kindergarten, private kindergarten, Christian kindergarten, and Islamic kindergarten, they do not have a curriculum that matches the characteristics of their institution. Based on the documents and interviews, there were $43 \%$ which showed that the curriculum centered on new children formulated, not seen in planning. Some principles of early childhood education according to Wood \& Hedges, (2016) wood, continue to have contemporary resonance such as: ECE centered on children - exploration, discovery, and research are drivers for learning and development; children learn through games and activities that are freely chosen, enabling them to develop independence, control, and autonomy; the curriculum includes all activities and experiences in the arrangement, including ethos, agreed rules, and behavior; practitioners identify children's interests and needs, and plan the curriculum in an emerging and responsive manner; the teacher can plan group activities to introduce certain curriculum content.

\subsection{Learning content or material in the curriculum.}

From the results of documents and interviews, the four kindergarten categories have no learning content, including mathematics, language, literacy, computers, art, science in the curriculum. One of the private kindergartens who became samples found content and learning materials in the curriculum but did not include it in curriculum documents. The interview results have no detailed explanation of their application. There are still inconsistencies in the translation of curriculum 
content. From the data, only $7 \%$ of the research objectives were consistent between the curriculum and activities consisting of content or learning material.

Wood \& Hedges (2016) suggested curriculum content in the substance of early childhood education, cannot be logically identified based on knowledge about the theory of child development, but looks for what subject matter should be taught. As according to Jacman (2012), early childhood curriculum content includes competency development content for children, namely, Communication in mother tongue, Communication in foreign languages, Mathematical competencies and basic competencies in science and technology, Digital competencies, Learning to study, Social competency and citizenship, Taste initiative and entrepreneurship, awareness and cultural expression.

\subsection{Curriculum used pays attention to children's needs.}

In private TK institutions and Christian kindergartens, their school principals stated that schools were concerned with the needs of children and this was stated in the curriculum documents they used. In Islamic kindergarten institutions, three kindergartens showed curriculum that pays attention to children's needs. It can be seen in curriculum documents on vision, mission and design activities while the public kindergarten curriculum emphasizes the fulfillment of children's needs and only one kindergarten that has no data.

Curriculum experts for early childhood, Dodge (2004) say making decisions about the right approach, curriculum model, and resources, the head of the program Education institutions must first consider the situation of their particular program. This includes examining: program vision / mission, philosophical beliefs held by the program (e.g., about how children learn best, how teachers grow professionally, family roles as partners in children's development and learning), mandates / requirements that must be met by the program (e.g., results, standards), staff experience and stability (for example, their ability to develop meaningful curricula, the guidance and training they will need) development (for example, time for teachers to meet together, share what they have learn about children, and engage in curriculum planning cooperation), available resources to support curriculum implementation (e.g., for material, staff development).

\subsection{Consistency and achievement of curriculum objectives by some children.}

Based on documentation findings, the consistency and achievement of curriculum objectives by several children is not available in four categories of kindergarten institutions, both general kindergarten, private kindergarten, Christian kindergarten, and Islamic kindergarten. The four kindergartens did not have supporting documents regarding these criteria.

According to Haslip \& Gullo (2018), repeated curriculum changes create extra work for teachers, confusion for parents and inconsistencies for children. Cost income for educational institutions can contribute to this landscape because education companies, consultants, and trainers try to sell a curriculum, approach, or solution above another. When communities appreciate the need and importance of early education, the education market is widening, attracting more vendors who claim evidence-based or research methods supported in their marketing materials. Concerns that education in general is rapidly becoming a consumer market that harms children and public goods have been discussed. Conflicts of interest need to be identified between establishments and educational institutions on the one hand and children on the other. Children need a deeper and meaningful consistency and learning experience based on community-based relationships. 


\subsection{Easiness curriculum implemented in the form of a daily learning program.}

Only one private nursery and some Islamic children's gardens have a curriculum that is easy to apply in everyday life. Preparation of semester planning, weekly, and daily systematically arranged. While other TK institutions do not have data that shows a curriculum that is easy to apply in daily life, it can be seen in curriculum documents that are not systematically arranged for semester planning, theme programs, weekly and daily plans.

This is in line with the research conducted by Burchinal (2018) that high-quality early care and education (ECE) programs are considered to increase opportunities for all children to succeed in school, but recent findings question whether these programs affect children in anticipation. They examine studies that link the quality of early childhood curriculum (EEC) with children's outcomes, finding a rather inconsistent and simple association with the process size and structural quality that is widely used, and a more consistent and strong relationship with other ECE dimensions such as curriculum and the type of EEC program. Evidence shows that we need to focus on the contents of teaching instruction and practice, and the extent to which teachers actively scaffold learning opportunities. We also need to continue to focus on the quality of interactions between teachers and children, and on children's access to activities that are age appropriate.

\subsection{The curriculum helps children build concepts and skills through a combination of topics and material.}

Based on the findings, only one private kindergarten and one Islamic kindergarten explained that curriculum helps children develop concepts and skills through a combination of topics and material. Plans for learning activities that prepared by the teacher showed a material explanation that will be delivered to the child. Other findings, in kindergarten institutions that do not have data available to see curriculum criteria to build concepts and skills through topics and material integration. The results of the interviews indicate that there is no information about the steps in preparing a learning program that is combined into a curriculum.

Even though the teacher is ideally involved in all phases, the special emphasis here is the process of applying the curriculum. For example, curriculum objectives might be to help teachers interpret students' thoughts about activities and content they design to teach; support teacher learning about content to build concepts and skills through topics and material integration, especially those that may be new to the teacher; and provides guidance on the external representation of the content used by the material. Sarama \& Clements, (2019) create classroom-based teaching experiments that help to track and evaluate student learning, with the aim of understanding activities that are in accordance with the curriculum. At the same time, classes are observed for information about the usefulness and effectiveness of the curriculum topics or themes with the material.

\subsection{Internalizing cultural values of Indonesian society in the curriculum.}

Based on the findings of private kindergarten institutions, there is only one kindergarten that internalizes the cultural values that exist in Indonesian society. It contained in curriculum documents, including; nationalism and traditional clothes. In Islamic and Christian kindergarten institutions, it shows that learning in kindergarten has not internalized the cultural values that exist in Indonesian society. They have not been detailed into the document. The range of cultural values is limited to nationalism, traditional clothes, life in the village and city. In the curriculum document found the theme of nationalism, but no specific theme indicates the cultural values that exist 
in Indonesian society. While the review results of public kindergarten, curriculum documentation indicate the existence of internalizing the cultural values that exist in Indonesian society. It can be seen in the selection of themes related to Indonesian culture. It means only $56 \%$ of the research objectives internalize cultural values in the curriculum.

The research conducted by Yang \& Li, (2019), namely the development of a school-based curriculum (SBCD) has been advocated to improve the quality of early childhood education in the context of modernization and globalization. However, several studies have examined how social change and globalization can shape the curriculum of early childhood. This study examined SBCD in the two Shenzhen kindergartens through interviews, observations and documents to understand curriculum innovation and how and why SBCD occurred in the Chinese capital. This study reveals that the curriculum in each case is an integrated system that balances different curriculum approaches such as the application of local culture. Also, conflict and cultural fusion are found throughout the dynamic transformation of the curriculum

\subsection{Curriculum skills in adapting technology and information development}

Based on evaluations in private kindergartens, only one private kindergarten institution whose curriculum adapts technology and information. It can be seen in learning activities that provide information to students. Islamic kindergarten institutions showed that the curriculum used does not specific adapt technology and information. It can be seen from the selection of themes such as communication, the feast of the sacrifice and the month of Ramadan, so the scope of learning is limited to modern communication tools. The curriculum for the Christian kindergarten and public kindergarten adapted technology and information development, but only on the theme development not detailed in curriculum documents and learning activities.

Mak, Keung, \& Cheung (2018) has identified five curriculum orientations for early childhood today, namely, academic, cognitive processes, social reconstruction, humanistic, and technology. In his research, Fox-turnbull (2007) reviewed the literature that argues the place for digital technology in the curriculum. Understanding and competency in developing digital technology has become an increasingly debated topic throughout the world. The area of debate includes where and when the main components of digital literacy such as computational thinking, computer science, programming, and coding must be studied. This article argues for the inclusion of digital technology in the curriculum and more specifically in the technology curriculum. A case study of New Zealand's decision-making process while moving to incorporate digital technology into the New Zealand Curriculum. When we go further into the digital era, there is international recognition of the need for digital technology in the curriculum. The introduction of digital competencies as an academic subject is a recent addition to early childhood, elementary and middle school programs in a number of countries such as Australia, England, Estonia and Cyprus. Any people believe that children need to be users of digital technology that is competent to avoid loss or marginalization and to become a guaranteed, discriminatory and effective member of society. Because it is time for early childhood curriculum to incorporate technology as a learning medium (Plowman, Stephen, \& Mcpake, 2010).

\section{CONCLUSION}

Kindergarten institutions that are the target of research in North Jakarta and Central Jakarta are divided into four categories. The four categories were Public kindergartens, Private kindergartens, Christian kindergartens, and Islamic kindergartens. The kindergarten only used references from 
the Minister of Education No. 58 of 2009. There were several institutions that directly adapt the government curriculum without reformulating the institution's curriculum.

Based on curriculum analysis related to curriculum development criteria, it concluded that:

The suitability of the curriculum used in learning, is in line with the aspects and stages of child development. $75 \%$ of public kindergarten institutions have the same curriculum form, not found in the characteristics of each institution. The rest do not have curriculum documents at all. Even though it has the same curriculum, there must be curriculum suitability between aspects of the child's development stage. The development aspects are not consistent between the curriculum and the structure of the learning program.

Curriculum orientation used is child-centered. Based on the findings of public kindergarten, private kindergarten, Christian kindergarten, and Islamic kindergarten, they do not have a curriculum that matches the characteristics of their institution. Based on the documents and interviews, there were $43 \%$ which showed that the curriculum centered on new children formulated, not seen in planning.

Learning content or material in the curriculum. From the data, only $7 \%$ of the research objectives were consistent between the curriculum and activities consist of content or learning material. There is no learning content, including mathematics, language, literacy, computers, art, science in the curriculum. content and learning material have been found in the curriculum but did not include it in curriculum documents. The interview results have no detailed explanation of their application. There are still inconsistencies in the translation of curriculum content.

The curriculum used is expected to pay attention to the needs of children. Based on document and interview result, private kindergarten, public kindergarten, Christian kindergarten, and Islamic kindergarten showed $69 \%$ pay attention to children's needs and contained. It can be seen in curriculum documents on vision, mission and design activities.

Consistency and achievement of curriculum objectives by some children. Based on the documentation findings, the consistency and achievement of curriculum objectives by some children are not available in the four categories of kindergarten institutions, both public kindergarten, private kindergarten, Christian kindergarten, and Islamic kindergarten. The four kindergartens did not have supporting documents regarding these criteria.

Curriculum facilitation is implemented in the form of daily learning programs. The document only lists themes, objectives, and activities in each age group. From the data, only $25 \%$ have an easiness curriculum to be implemented in everyday life. Preparation of semester planning, weekly, and daily systematically arranged. While other kindergarten institutions have no data that shows the easiness curriculum to implement in everyday life. It can be seen in curriculum documents that not systematically arranged for semester planning, theme programs, weekly and daily plans.

The curriculum helps children build concepts and skills through a combination of topics and material. $12.5 \%$ for explaining the curriculum helps children build concepts and skills through a combination of topics and material. Plans for learning activities that prepared by the teacher showed a material explanation that will be delivered to the child. The findings of other kindergarten institutions have no data available to see the criteria for building concepts and skills through topics and material integration. The interview results showed that there was no information about the steps in preparing a program that combined topics or themes with the material. 
Kindergarten institutions are expected to be able to internalize the cultural values of Indonesian people in the curriculum. Only $56 \%$ of the research objectives internalize cultural values in the curriculum. It contained in curriculum documents, including; nationalism and traditional clothes. The content has not been specified in curriculum documents. The range of cultural values is limited to nationalism, traditional clothes, life in the village and city. In the curriculum document found the nationalism theme, but no specific theme indicates the cultural values that exist in Indonesian society.

Curriculum skills in adapting technology and information development. 25\% of kindergarten institutions whose curriculum adapts technology and information. Information. It can be seen from the selection of themes such as communication, the feast of the sacrifice and the month of Ramadan, so the scope of learning is limited to modern communication tools. However, it is only included in the development of daily themes and is not specified in curriculum documents and learning activities.

\section{REFERENCES}

Burchinal, M. (2018). Measuring Early Care and Education Quality. Child Development Perspectives, 12(1), 3-9. https://doi.org/10.1111/cdep.12260

Dhieni, N., \& Utami, A. D. (2013). Evaluasi Konten Kurikulum Taman Kanak-Kanak di DKI Jakarta Tahun ke 1 dari rencana 3 tahun. Jakarta: FIP press.

Dodge, D. T. (2004). Early Childhood Curriculum Models Why What and How Programs Use them. Exchange Organizational Behavior Teaching Journal, (February), 71-75.

Eliason, C., \& Jenkins, L. (2008). A Practical Guide to Early Childhood Curriculum 8th. New Jersey: Pearson Prentice Hall.

Fox-turnbull, W. (2007). Implementing Digital Technology in The New Zealand Curriculum.

Gestwicki, C. (2007). Developmentally Appropriate Practice Curriculum, and Development in Early Education 3rd Ed. New York: Thomson Delmar.

Hainstock, E. G. (2002). Montessori untuk Prasekolah. Jakarta: Pustaka Delapratasa.

Hasan, S. H. (2008). Evaluasi Kurikulum. (U. \& R. Rosdakarya, Ed.). Bandung.

Haslip, M. J., \& Gullo, D. F. (2018). The Changing Landscape of Early Childhood Education: Implications for Policy and Practice. Early Childhood Education Journal, 46(3), 249-264. https://doi.org/10.1007/s10643-017-0865-7

Jackman, H. L. (2012). Early Education Curriculum: A Child's Connection to the World Fifth Edition. Belmont: Wadsworth: Cengage Learning.

Jacman, H. (2012). Early Education Curriculum. Pedagogical Development Unit, (FEBRUARY 2011), 163. Retrieved from https://www.eursc.eu/Syllabuses/2011-01-D-15-en-4.pdf

Kostelnik, M. J., Soderman, A. K., \& P, A. (2007). Whiren, Developmentally Appro-priate Curriculum: Best Practices in Early Childhood Education 4th. New Jersey: Pearson Prentice Hall.

Mak, B., Keung, C., \& Cheung, A. (2018). Analyzing Curriculum Orientations of Kindergarten Curriculum. In Teacher Education, Learning Innovation and Accountability, (pp. 135-153). Singapore: Springer Singapore. https://doi.org/10.1007/978-981-13-2026-2

Odom, S. L., Butera, G., Diamond, K. E., Hanson, M. J., Horn, E., Lieber, J., ... Marquis, J. (2019). Efficacy of a Comprehensive Early Childhood Curriculum to Enhance Children's Success. Topics in Early Childhood Special Education. 
https://doi.org/10.1177/0271121419827654

Plowman, L., Stephen, C., \& Mcpake, J. (2010). Growing Up with Technology (pp. 1-169). London and New York: Routledge.

Roopnarine, J. L., \& Johnson, J. E. (2005). Approaches to Early Childhood Education 4th Ed,. New Jersey: Pearson Prentice Hall.

Sarama, J., \& Clements, D. H. (2019). From Cognition to Curriculum to Scale. Cognitive Foundations for Improving Mathematical Learning. https://doi.org/10.1016/b978-0-12815952-1.00006-2

Wood, E., \& Hedges, H. (2016). Curriculum in early childhood education: critical questions about content, coherence, and control. Curriculum Journal, 27(3), 387-405. https://doi.org/10.1080/09585176.2015.1129981

Yang, W., \& Li, H. (2019). Changing culture, changing curriculum: a case study of early childhood curriculum innovations in two Chinese kindergartens. Curriculum Journal, $O(0)$, 1-19. https://doi.org/10.1080/09585176.2019.1568269 